\title{
IMPORTÂNCIA E APROVEITAMENTO DA ORGANIZAÇÃO INFORMAL
}

WITT, A. - Importância e aproveitamento da organização informal. Rev. Saúde públ., S. Paulo, 3(2):203-212, dez. 1969.

RESUMo - Ao lado da organização formal, reconhece-se hoje a existência de uma organização informal bastante influente nos destinos de qualquer instituição. Há uma série de semelhanças entre os dois tipos de instituição, merecendo destaque a estrutura de relacionamentos, os sistemas de contrôle e comunicação, a existência de pessoas com autoridade, a permanência relativa de seus membros e a possibilidade de representação gráfica. Como essa organização informal é indestrutível, recomenda-se seja ela utilizada pela formal, o que, além de viável, é altamente vantajoso para a instituição como um todo. São expostas algumas formas de estudo e utilização da organização informal.

\section{N T R O D U C A O}

Um tipo de instituição social, bastante difundido no presente, é aquêle baseado na autoridade burocrática, também chamada racional legal. Tôda a estrutura e funcionamento de tal instituição estão calcados na ordem legal, entendida esta como um sistema impessoal, consistente $e$ intencionalmente estabelecida. Para poder funcionar, êste tipo de instituição exige a existência de uma es. trutura com clara delimitação de poderes e deveres, sistema de méritos, etc.

O sistema social de saúde encaminha-se visivelmente no sentido da burocratização, o que constitui indício de modernização. Aos dirigentes dos serviços sanitários deve interessar de perto o funcionamento real daquele sistema, especialmente se atentarmos à ênfase que os pla- nejadores do setor saúde dão ao bom aproveitamento dos recursos existentes. Entre tais recursos, destaca-se a organização humana, cujo aproveitamento é facilitado pelas ciências sociais, que fornecem elementos valiosos acêrca do comportamento dos indivíduos que constituem a viga-mestra das organizações.

\section{ORGANIZACAO FORMAL E INFORMAL}

O comportamento dos sêres humanos pode ser estudado sob vários ângulos, sendo um dêles, aquêle resultante de sua vida interativa com outras pessoas. E esta uma abordagem sociológica, onde o comportamento corresponde à "maneira de agir que o homem adquire pela vida

Recebiđo para publicação em 1-9-1969.

(1) Da Disciplina Autônoma de Ciências Sociais Aplícadas da Faculdade de Higiene e Saúde Pública da USP, Săo Paulo - Brasil. 
WITT, A. - Importância e aproveitamento da organização informal. Rev. Saúde pübl., S. Paulo, 3(2):203-212, dez. 1969.

social, o que o distingue das outras espécies animais" " Os modos de agir explicados desta forma, tornam claras muitas situações sociais.

0 homem tem, como características fundamental, uma existência associativa com seus semelhantes, para a satisfação de suas necessidades. A associação é uma forma básica de interação social, que leva à formação de grupos. Desta convivência resultam comportamentos específicos, que mostram existirem relacionamentos importantes não só entre os in. divíduos componentes de um grupo como também entre os próprios grupos. Podemos dizer que os individuos encontram-se normalmente agrupados, em unidades com formas diferentes, apresentando cada qual características próprias, iden. tificáveis, decorrentes de um sistema de relações particular.

Existe uma influência recíproca de comportamentos entre os elementos componentes de um grupo. Esta influência está diretamente ligada ao tipo de contato social existente entre os indivíduos, que pode ter maior ou menor distância social. () comportamento dos indivíduos é também sensível à dimensão do grupo e à freqüência dos contatos, havendo uma maior pressão para o seguimento das normas e consequiente uniformidade de comportamento, quando é pequeno o número de membros e são frequientes os contatos. Serviriam como exemplo, as diferenças existentes entre as relaçōes predominantes no meio rural e no meio urbano. O meio rural se caracteriza por uma homogeneidade, e o urbano por uma heterogeneidade.

Com o crescimento das sociedades, aparece uma grande variedade de grupos, desenvolvendo-se, paralelamente, associações com organizações complexas, visando à consecução de objetivos específicos. Essas organizaçōes passam a ter uma pretensa base racional, onde os grupos e os indivíduos possuem posiçōes e papéis definidos a priori; seu funcionamento baseia-se na divisão do trabalho segundo ca- pacidades, e há também uma estrutura de autoridades. Estas dimensões têm grau de desenvolvimento diferente de uma organização para outra.

Através desta organização, denominada, geralmente, formal ${ }^{4}$, procura-se a obtenção de um objetivo proposto, através do comportamento adequado dos indivíduos.

A organização formal define os padrões de relacionamento, fixando-os em regulamentos e leis.

As relações são concebidas de maneira impessoal, com as características de contatos secundários, ou seja, ligações indiretas, formais, deliberadas, racionais, categorizadas. 0 sistema de normas regulamentado contribui para a eliminação das hostilidades provenientes de ações baseadas em vínculos afetivos, que podem ser prejudiciais aos demais componentes da organização. Através da definição clara dos direitos e deveres, pretende-se, também, obter uma maior precisão e eficiência na execução das tarefas. Realmente, sendo enunciadas tôdas as atividades, existindo um sistema de procedimentos, as normas de conduta ficam claras, facilitando a ação dos membros componentes da organização.

Os organogramas constituem a representação gráfica desta organização, devendo conter suas unidades estruturais $\mathrm{e}$ relações funcionais. Os indivíduos ou grupos aparecem ordenados, com diferentes níveis de autoridade e respectivas linhas de relações. São projetadas esquemàticamente, a estrutura $e$ as relaçōes que se pretendem estabelecer.

Mas não podemos perder de vista o fato das organizaçôes formais serem compostas de indivíduos que apresentam diversidade de comportamentos, estando o alcance das metas específicas também condicionado à ação de agrupamentos sociais.

$\mathrm{Na}$ realidade, os indivíduos colocados nas unidades estruturais, segundo as necessidades da organização formal, ao começarem a atuar, dão a esta última uma forma diferente da fixada legalmente. A 
WITT, A. - Importâncla e aproveitamento da organização informal. Rev. Saúde públ., S. Paulo, 3(2):203-212, dez. 1969.

interação decorrente do funcionamento da entidade cria um relacionamento distinto. Verifica-se que, além do aspecto formal, há um informal, sendo o primeiro, campo de atuação do administrador, enquanto que o segundo oferece maior interêsse para os sociólogos. Êstes focalizam as relações não convencionais que existem nas organizações, dando atenção às facêtas formais, apenas na medida em que afetam os processos sociais, ou são afetados por t̂les. Os padrões de relações são estudados como realmente ocorrem, nos diferentes níveis e entre êles, de acôrdo óu não com o prescrito. Poderia ser dito que a estrutura formal diz respeito aos aspectos técnicos da organização, enquanto que a informal aos humanos, tendo, de acôrdo com as afirmações de BARNARD $^{2}$, a primeira uma coordenäção proposital, não havendo na segunda, uma aliança consciente.

Qualquer organização, constituindo um sistema de contatos com graus diferentes de aproximação entre os membros, dá origem à formação de grupos com características próprias.

O grupo social primário se encontra, de uma forma ou outra, no interior de todo sistema, mesmo nos bastante desenvolvidos e altamente planejados. Atualmente, um bom exemplo de tal grupo, além dos clássicos citados por Cooley - família, grupo de briquedo e de vizinhança de pequenos centros - é o grupo de trabalho. Este é parte constituinte da organização formal, necessária ao seu funcionamento; tem características de grupo primário, entre elas, a informalidade. Porém, o fato de ser um grupo informal não quer dizer que não seja organizado, sendo a organização um atributo exclusivo dos grupos formais de uma entidade. Os indivíduos componentes dos grupos sociais pròpriamente ditos, apresentam sempre relações organizadas, podendo-se dizer que a organização formal é uma realidade racional e que a organização informal é uma realidade social,

\section{SEMELHANCAS ENTRE A ORGANIZACARO} FORMAL E A INFORMAL

Existe uma série de características encontradas nos dois tipos de grupos, formais e informais, que indicam estarem os últimos bem próximos dos primeiros, ou seja, possuirem os grupos informais, também, uma organização definida.

Nos grupos formais, racionais, além da especificação das atividades dos membros, procura-se garantir sua realização através de normas disciplinares descritas e conhecidas. $O$ contrôle das ações é exercido através da atribuição de recompensas ou repreensões prescritas por regulamento. 0 indivíduo sabe que lhe é desvantajoso não agir conforme o esperado oficialmente, estando a aceitação do seguimento das normas sujeita, em grande parte, ao poder das sanções. Existem, na organização, pessoas dotadas de autoridade, que repre. sentam o poder coordenador, responsáveis pela divisão do trabalho, pelo contrôle, pelo seguimento das normas. Os indivi. duos, geralmente, orientam suas ações em têrmos do comportamento que dêles se espera, uma vez que conhecem as consequiências de uma conduta diferente. As. sim, têm conhecimento dos atos que podem gerar promoções, transferências ou suspensões.

Nas organizaçôes, a fim de que todos os indivíduos possam agir de conformidade com o esperado, são estabelecidas linhas de comunicação entre os diferentes grupos e indivíduos, as quais funcionam como canais de informação e transmissão de decisões. Quando a organização é com. plexa, contando com grande número de componentes, é impossível a transmissão individual das comunicaçōes; passam a ser impessoais, feitas, freqüentemente, por meio de cartas, panfletos, circulares, ou outros meios similares.

Analisando a organização informal, vemos que também nela existe sanção social, expectativa de comportamento, autoridade, comunicação e percepção da conseqüência de determinada forma de agir. 
WITT, A. - Importancia e aproveitamento da organização informal. Rev. Saúde públ., $\mathbf{s}$. Paulo, 3(2):203-212, dez. 1969.

Estabelecendo um paralelo entre a organização formal e informal, vemos que na primeira as sanções são regulamentadas expressamente, enquanto que na segunda, são difusas. Nestas o indivíduo tem seu comportamento controlado pelos demais, por meio de comentários, zombarias, reprovações, elogios, etc. Este contrôle informal é típico dos grupos primários, células básicas das organizações humanas, contrastando com as caracterís. ticas das organizações racionais, de natureza predominantemente secundária.

Os relacionamentos nos grupos primários são pessoais e profundos, atingindo intensamente o indivíduo, alcançando seus sentimentos e atitudes; as experiências são compartilhadas, assumindo cada membro o papel dos outros.

É claro que em tal situação social, onde existe uma estreita ligação dos membros, há pràticamente uma imposição de comportamentos, condicionada às expectativas do grupo; o indivíduo passa a agir em têrmos do comportamento esperado. Neste meio social, as atençóes de cada membro da organização estão centralizadas nos outros, o que funciona como mecanismo condicionante das respectivas ações. Verifica-se que é grande a fôrça de tais grupos, em comparação com a daqueles em que predominam os contatos secundários, uma vez que cada indivíduo procura fazer com que sua ação seja o reflexo da conduta esperada pelos membros do grupo.

Por outro lado, as autoridades informais, não em função do cargo que exercem, mas das suas qualidades pessoais, influem decisivamente no modo de agir das pessoas que compõem a organização formal. Têm elas uma superioridade efetiva, havendo grande probabilidade de serem seus pontos de vista aceitos sem discussão, automàticamente, por constituirem uma autoridade reconhecida e aceita, naturalmente, pelo grupo.

Assim como na organização formal, na informal também encontramos comunicação entre os membros, sendo ela um dos processos sociais básicos da sociedade e que favorece muito a associação. A comunicação é uma relação informal bastante significativa, porque aparece invariàvelmente em tôdas as organizaçóes formais. É conhecida, entre os administradores, por "rêde de informaçōes" e tida como indestrutível, uma vez que continua existindo por mais que se aperfeiçoe a comunicação formal. Uma de suas características é a de ser um meio de comunicação mais rápido que o legal, o que constitui um indicador satisfatório de sua importância. A comunicação é facilitada nos grupos informais; pelo tipo de contato neles existente, que é mais ou menos freqüente, dispensando local próprio para reunião e diferenças hierárquicas entre os membros. Através das comunicações nos grupos primários, surgem as atitudes de lealdade e identidade entre os indivíduos.

\section{AFROVEITAMENTO DA ORGANIZAÇAO INFORMAL}

Os homens e as máquinas em conjunto constituem o sistema de produção, sendo, portanto, necessário levar em consideração elementos humanos e técnicos, quando se pretende entender o processo produtivo global.

O desperdício do capital humano nas emprêsas vem constituindo, ùltimamente, uma preocupação dos estudiosos da administração. Isto porque é notório ser a verdadeira riqueza de qualquer socieda. de, grande ou pequena, o seu capital humano.

Visando um melhor aproveitamento dos recursos humanos, são desenvolvidas diversas atividades, dentre as quais se des. taca a prestação de assistência médico-social e treinamento específicos, tendo em vista evitar desperdício de tempo e de capacidades. Na verdade, além destas dimensões, outras devem ser observadas, considerando-se o potencial humano na sua totalidade, abrangendo os relacionamentos sociais. 
WITT, A. - Importância e aproveitamento da organização informal. Rev. Saúde públ., S. Paulo, 3(2):203-212, dez. 1969.

Sabe-se que, nas grandes organizações da atualidade, baseadas nas estruturas racionais, existem, por fôrça de sua matéria prima, indivíduos. Êstes passam a compor grupos particulares, que se identificam por sua constituição, definida em têrmos de relacionamentos: pouca ou grande distância social. Em decorrência de sua estrutura, surgem comportamentos específicos padronizados. Sem dúvida, esta organização informal influi grandemente na organização formal estabelecida; pode-se dizer que a eficiência resulta da soma das duas organizações, sendo maior ou menor de acôrdo com a interação que se processa entre elas. As grandes associações, planejadas objetivamente, vêm o comportamento de seus membros, apesar de tôda a racionalização, cair na esfera informal. bem verdade que também a organização formal influi na informal, favorecendo ou não os contatos humanos. Apesar de todos os cuidados tomados, não se conseguiu eliminar o aparecimento de relações informais. Desta forma, é aconselhável que se procure utilizá-las. 0 conhecimento dos processos sociais, que ocorrem entre os grupos humanos, nos permite aproveitar as fôrças favoráveis existentes.

Sabemos que o homem tende a se associar para a satisfação de suas necessidades, em qualquer situação profissional, e que a frequêencia de seus contatos pode levar à formação de grupos primários. Nestes, as relações são sobejamente superiores às encontradas nos grupos secundários, conferindo ao comportamento dos indivíduos características importantes, uma das quais é a identificação do indivíduo com o grupo. Pode mesmo surgir um entusiasmo coletivo, denominado pelos sociólogos de "esprit de corps", que é uma forma de consenso social, onde há grande solidariedade, decorrente do conhecimento de se ser membro de um grupo e que se acentua quando o grupo é muito considerado na sociedade. $O$ sentimento de participar de um grupo, particularmente apreciado atinge, portanto, diretamente o comportamento; os indiví. duos unem-se na defesa de seus valores, indo contra as determinações que acreditam ser prejudiciais, muitas vêzes, originárias da organização formal. Mas o comportamento dos indivíduos não precisa, necessàriamente, atingir de forma desfavorável as atividades desejadas oficial. mente; os objetivos da organização formal podem ser transformados, também, em objetivos da organização informal. Então, os grupos primários serão auxiliares poderosos da administração, fazendo aumentar consideràvelmente $\mathrm{o}$ nível de produção, num ambiente harmonioso com pequeno índice de "turn-over", ou seja, mudança de pessoal, mobilidade de emprêgo.

Como nas organizações se aspira à coordenação das atividades individuais, condição esta necessária para o alcance do objetivo, devem ser observados os padrões de comportamento característicos dos grupos e o tipo de relacionamento existente entre êles. Muito será conseguido se a satisfação de pertencer a um grupo informar puder ser transportada para a organização formal. Aqui, é particularmente importante a ação dos líderes informais, que têm a capacidade de influenciar profundamente o modo de agir do grupo.

Tôdas as associações que desejam uma atuação adequada e harmoniosa de seus membros, de acôrdo com os regulamentos da entidade, devem fazer uso da fôrça das lideranças. Liderança é um fenômeno que traz em si a idéia de capacidade de influenciar as pessoas. Pode aparecer em qualquer ponto da organização, exercendo grande contrôle difuso e conduzindo o grupo à realização de suas metas. Cada organização tem seu objetivo específico, que pode ser econômico, educacional ou outro qualquer. $O s$ indivíduos, por sua vez, também têm objetivos particulares, que se ligarão com os da organização, se houver algum ideal básico somum. A dedicação aos deveres inerentes à posição na organização só será satisfaiória se sustentada por sentimentos que assegurem tal dedicação. Estes sentimentos podem ser desenvolvidos nas associações informais, através do espírito gru- 
WITT, A. - Importância e aproveltamento da organização informal. Rev. Saúde públ., S. Paulo, 3(2):203-212, dez. 1969.

pal, que ocorre nas relações primárias. A lealdade para com as normas decorre da identificação do indivíduo com os princípios de seu grupo primário; é aqui que se formam os sentimentos, que serão expressos nas relaçōes secundárias, existen. tes nas organizações formais. Assim, a solidariedade dos grupos secundários depende do papel desempenhado pelos primários, que controlam, em grande parte, o comportamento de seus participantes. Uma boa forma de aproximação das duas organizações seria o aproveitamento dos líderes que surgem naturalmente. São portadores de grande autoridade e deveriam ser transformados em líderes formais, ou seja, autoridades legais. Quando não houver esta possibilidade, é acon. selhável que o chefe formal seja treinado no exercício da liderança. É provável que seja mais fácil treinar um líder natural para o exercício da chefia, do que treinar chefes para serem líderes. No primeiro caso, é necessário dar conhecimentos adicionais ao indivíduo, enquanto que no segundo, muitas vêzes, se faz necessário substituir conhecimentos, atitudes e valores.

Outro ponto a ser observado e considerado pela organizaçäo formal é o que se refere à comunicação. Como já foi visto, existem canais informais de transmissão de informaçōes. Através dêste tipo de comunicação, conhecimentos diversos circulam entre os indivíduos. Porém, não se reduz a operação à simples transmissão de algo; a mensagem pode sofrer modificaçôes no seu transcurso, desenvolvendo. -se nos grupos sentimentos favoráveis ou năo ao que foi transmitido. A importância disto se torna evidente se nos repor. tarmos às características dos grupos primários, onde existe uma grande tendência de identificação dos individuos entre si, aliada a intenso contrôle social sôbre fa. tos triviais. Assim, há grande possibilidade de qualquer comunicação, que seja do interêsse do grupo, ser logo aceita, sendo rejeitada a que não lhe convier. Cumpre à organização formal aproveitar êstes canais, para mais fàcilmente e com maior rapidez alcançar seus objetivos. Isto pode ser conseguido através da colo. cação de um indivíduo-chave na cadeia de comunicação informal. Outra vanta. gem, decorrente dêste procedimento, seria a prestação de informações da organiza. ção informal à formal, facilitando às auto. ridades legais a tomada de decisões acer. tadas.

\section{FORMAS DE ESTUDO}

0 estudo da organização informal tem interessado um número considerável de cientistas, tendo seus trabalhos, geralmente, focalizado atividades industriais. Todavia, os princípios expressos por tais estudiosos são de grande importância para qualquer organização, sendo interessante e, talvez mesmo, necessário, seu emprêgo no setor saúde. Éste setor, através das técnicas de planejamento que atualmente utiliza, traz à baila o problema econômico do uso adequado dos recursos escassos, entendendo-se por recursos, não só os fatôres materiais e técnicos, mas também os humanos. Uma das formas de bom aproveitamento do recurso humano, que representa 60 a $80 \%$ dos gastos do setor, seria a utilização da organização informal, que é a mais poderosa influência que dirige o comportamento do indivíduo.

Seguindo a terminologia do planejamento, onde os setores são classificados, quanto à função de produção de bens $e$ serviços, em econômicos (indústria, energia, agricultura, transporte, comunicaçãa, comércio exterior) e sociais (educação, saúde, habitação, previdência social), afirmamos que seria interessante o aproveitamento dos princípios aplicados ao setor econômico-industrial, pelo setor social da saúde. Isto é viável, uma vez que são encontradas semelhanças entre os dois setores: existe, tanto na instituição quanto na emprêsa pública, uma produção de bens e serviços, da mesma forma que na emprêsa particular. Entende-se por instituição pública um "organismo público criado por disposição legal para produzir bens ou serviços, operando sob a modalidade 
WITT, A. - Importância e aproveitamento da Rañização informal. Rev. Saúde públ., $\mathbf{S}$. Paulo, 3(2):203-212, dez. 1969.

de propósito de govêrno e, portanto, podendo entregar sua produção gratuitamente ou a uma taxa nominal" (1) e por emprêsa pública um "organismo público, criado por disposição legal para produzir bens ou serviços, porém operando como emprêsa de lucro e sôbre bases comerciais $e$, portanto, vendendo sua produção a preço de mercado" (1). Tal como nas emprêsas econômicas industriais, também nas instituiçōes e emprêsas públicas ou privadas que produzem serviços de saú. de, é encontrada uma máquina adminis. trativa e operacional, montada formalmente que, sem dúvida, contém uma organização informal. Esta organização no setor saúde, de modo geral, não tem recebido a atenção que merece, fato êste evidenciado ao nos reportarmos, comparativamente, aos trabalhos realizados nas indústrias.

Entre as várias formas de estudo da organização informal, temos a sugerida por Miller \& Form ${ }^{8}$. Segundo êles, a técnica que permitiria analisar a organização informal seria a da observação das relações sociais existentes na organização.

Fica claro que o que merece aten. ção não são os indivíduos pròpriamente, mas seu comportamento visto numa pers. pectiva interacionista.

E feita uma classificação das ações dos indivíduos, que podem ser técnicas, sócio-técnicas e sociais. As técnicas dizem respeito, exclusivamente, às significaçōes que são dadas ao exercício das mesmas; o comportamento técnico não envolve interação. Por sócio-técnicas, entendem-se as açṍes que incluem relacionamento huma. no na sua execução; são determinações formais aproximando pessoas no exercício de suas funções. A ação social baseia. -se na amizade, não decorrendo, a interação existente, do desempenho das atividades. Fazem parte da organização formal, o comportamento técnico e o sócio-técnico, enquanto que o social constitui a organização informal. Há, no entanto, facilidade para a ação sócio-técnica se converter em ação predominantemente social.

0 interêsse do investigador se centraliza no último grupo de comportamento citado, passando a observar o trajeto dos relacionamentos, as reações mútuas e o que disto resulta. Na aplicação desta técnica de observação, recomenda-se que 0 pesquisador se mantenha fora do grupo, o máximo possivel, evitando tornar-se, êle mesmo, um elemento da organização. Mas, não seria mais adequada a utilização da observação participante para o levantamento da organização informal, seguindo os passos propostos? Neste caso, far-se-ia necessária uma co-participação consciente e sistemática do pesquisador, sendo os dados referentes ao comportamento dos membros da organização obtidos diretamente; para tal, o pesquisador deve ser considerado membro do grupo, pelos demais elementos ${ }^{6}$. E possível que por meio dêste método seja mais fácil e completa a obtenção do conhecimento das atitudes e comportamentos reinantes entre os membros da organização informal. $O$ fato do investigador ficar fora do grupo pode dificultar o entendimento da situação real, não permitindo uma visão dos interêsses e emoções das pessoas estudadas ("insight"), faltando aos dados coletados maior objetividade. $O$ método da observação participante também tem suas limitações e desvantagens, as quais podem ser bastante diminuídas, especialmente se controlado o "bias".

Através do micrograma, que é a representação gráfica mínima possivel de cada cargo profissional, pode-se levantar a estrutura funcional da emprêsa. Este estudo foi desenvolvido por Puigvert ${ }^{10}$, partindo dos ergogramas, que são as representações gráficas das relações existentes em cada pôsto de trabalho.

(1) "Técnica de programação do setor público". Trabalho apresentado no II Curso de Especializaçáo em Planejamento do Setor Saúde - Faculdade de Higlene e Saúde Pública da USP, 1969. 
WITT, A. - Importância e aproveitamento da organização informal. Rev. Saúde públ., s. Paulo, 3(2):203-212, dez. 1969.

O micrograma tem por base a representação das relações de cada pôsto, ligadas a 3 níveis: superior, razante e in. ferior. Dizem respeito, respectivamente, às relações existentes com o chefe imediato, com os indivíduos da mesma catego. ria e com os subordinados.

Cabe salientar que o que se procura não são as relações teóricas existentes na organização geral, mas aquelas que realmente existem na prática. $O$ ideal seria que a representação dos dois relacionamentos fôsse a mesma, mas isto raramente acontece. Por exemplo, ao lado do sistema de comunicação teòricamente criado, existe, em parte, outra corrente de informaçōes que pode não estar em concordância com a anterior. É feita uma comparação das duas estruturas, sendo anotadas as anomalias existentes. A seguir, os resultados podem ser usados com grande proveito para todos. Segundo Puigvert ${ }^{10}$, os microgramas permitem: "corrigir acumulaçōes desnecessárias de pessoal; limitar as chefias às justas; controlar os canais de informação; delimitar as funções, evitando duplicidade; produzir bem-estar ao trabalhador pelo restabelecimento de uma ordem natural; permitir aproveitar ao máximo as fôrças humanas sem perdas por trabalhos duplicados ou sem ordem de direção da emprêsa; conhecimento das necessidades de substituir ou modificar o pessoal das seções".

Através do micrograma, consegue-se levantar, de certa forma, parte da estrutura da organização informal de uma emprêsa, especialmente a referente à comunicação $e$ relações funcionais. $O$ principio desta técnica poderia ser estendido a outros campos da organização informal, permitindo o conhecimento de fôrças sociais adicionais de interêsse para o empresário $e$, conseqüentemente, para os funcionários.

Uma forma de estudo, parcialmente semelhante ao micrograma, que inclui re- presentação gráfica, é a técnica de análise das distorções da estrutura formal ${ }^{(1)}$. Esta técnica faz parte dos estudos da Organização e Métodos $(O \& M)$, abrangendo as técnicas de organogramas típicas de $0 \& \mathrm{M}$ e sociograma, esta última de índole psico-social, criada por Moreno. Parte da hipótese de que a organização tem duas estruturas, uma formal, decorrente da intenção deliberada do grupo que a criou, e uma informal, proveniente dos processos sociais de interação, oriundos do funcionamento da organização formal. A estrutura informal é estudada, considerando os diferentes processos sociais que tendem a alterar a organização formal, vindo cada qual a constituir uma forma de organização particular, que é representada gràficamente. Estas formas de organização informal, são fixadas em padrões ou camadas ${ }^{9}$ que se sobrepõem à estrutura formal. Cada um dêstes padrões ou camadas é desenhado em papel trans. parente, com tinta de côr diferente. Quando não houver distorções, ao serem colocados os papéis transparentes, com os respectivos desenhos, sôbre o organograma fundamental, que é o formal, as linhas se sobrepõem, coincidem.

Portanto, onde não houver concordância de linhas há distorção, ou seja, afastamento da estrutura formal. Os cinco padrões mais estudados são: das relações empáticas, das relações funcionais, do processo de decisão, dos centros de poder e dos canais de comunicação. Para o levantamento do primeiro padrão, relativo às relações empáticas, é usado o teste sociométrico. Para os demais, é possivel o emprêgo de questionário, formulário, entrevista, ou observação participante, yariando a escolha da técnica, de acôrdo com o tipo de pesquisa, as possibilidades materiais e humanas, o tamanho e composição da organização.

(1) Apontamentos de aula sôbre Elementos de Administração, ministrada pelo Dr. Reinaldo Ramos, no II Curso de Especialização em Planejamento do Șețor Saúde, Faculdade de Higiene e Saúde Pública da USP, 1969. 
WITT, A. - Importância e aproveitamento da organizaçăo informal. Rev. Saúde públ., $\mathbf{s}$. Paulo, 3(2):203-212, dez. 1969.

HAIRE $^{5}$ chama a atenção para a necessidade de ser reexaminada a estrutura das organizaçōes, propondo que as mesmas sejam construídas tomando por base os grupos humanos, afirmando que, em última análise, a organização se encontra no grupo e não no trabalho, sendo que êste se objetiva em função daquele.

As pessoas devem ser organizadas de forma a executar um trabalho, ao invés dêste ser planejado racionalmente, em têrmos exclusivos, de cargos e funçōes com normas descritas. Haire endossa o parecer de Likert ${ }^{7}$, que sugere ser necessária, na estrutura básica, a existência de relações entre os diferentes níveis hierárquicos, aproximação esta feita por indivíduos tidos como "elos de ligação", os quais ocupam postos de chefia. Êstes indivíduos precisam pertencer tanto ao grupo superior quanto ao inferior. Verifica-se ser fundamental a existência de grupos na organização, a fim de que o "elo" possa a êles pertencer e tornar possível a ligação. Acidentalmente, podem surgir organizaçôes com tal característica; geralmente, os indivíduos não são encontrados com uma estrutura desta natureza, havendo necessidade de se lançar mão de especialistas, para a sua composição. Estes poderão levantar a estrutura da organizaçảo informal existente, conhecimento êste necessário para a compreensão das atividades grupais. Certamente, na grande maioria das vêzes, será preciso remanejar as pessoas da organização, para que se consigam grupos com as características desejáveis; além disto, sem dúvida, haverá necessidade de se dar um treinamento especial aos indivíduos da emprêsa, focalizando, por exemplo, trabalho em grupo, liderança, relações humanas.

Procura-se construir estruturas grupais satisfatórias, que são necessárias para o alcance mais fácil do objetivo da emprêsa, sendo esta uma forma de aproveitamento da estrutura informal.

P'adrões de interação social podem ser obtidos pelo teste sociométrico e representados gràficamente nos sociogramas.
Através dêles, podem ser identificados os núcleos sociológicos existentes na organização, sendo de grande importância para a montagem da estrutura proposta por LiKERT ${ }^{7}$, o conhecimento dos núcleos de polarização. Estes podem ser de primeiro grau, quando grande número de escolhas recai sôbre um indivíduo, e de segundo grau quando um indivíduo é escolhido relativamente por poucos indivíduos, mas êstes são polarizados primàriamente.

É importante constituirem os indivíduos "elos de ligação" núcleos polarizados; só assim conseguem desempenhar suas, funções de modo satisfatório. A sociometria é bastante útil para o levantamento da organização informal, sendo seu uso particularmente indicado no estudo das distorções da organização formal (método descrito anteriormente), para a obtenção do padrão ou camada correspondente às relações empáticas; também fornece resultados importantes para a construção de um organização baseada na ligação dos diversos níveis hierárquicos, indicando quais são as pessoas mais adequadas para constituirem a ponte de união.

Pelo exposto, verifica-se que a vida humana tem por base a organização. Para o entendimento perfeito dos comportamentos dos indivíduos nas emprêsas, devemos atentar para a organização formal, para a informal e para as relações existentes entre elas. Só assim teremos o conhecimento exato da organização. 0 comportamento decorrente da interação dos dois tipos de organização passou a interessar muito aos cientistas da atualidade, começando-se mesmo a falar em "comportamento organizacional" ", que corresponde ao comportamento observado, decorrente da fusão da organização informal com a formal.

Bastante importante é a formação de grupos dentro das emprêsas e o aproveitamento dos já existentes para um bom emprêgo do capital, uma vez que a êles se liga diretamente a produção. Fica implícito que, ao lado de um maior rendimento, é criado um ambiente social mais favorável aos indivíduos, sendo atendidas 
WITT, A. - Importancia e aproveitamento da organizaçăo informal. Rev. Saúde públ., S. Paulo, 3(2):203-212, dez. 1969.

suas necessidades humanas básicas. Pro. cura-se um equilíbrio significativo entre produção e relações humanas. Princípios sociológicos devem ser considerados nas organizaçōes pelos administradores, ficando claro que os cientistas sociais precisam, também, levar em conta a organização formal, para o entendimento exato da questão.

Recomenda-se à Saúde Pública que lance mão dêstes recursos, atualmente existentes, sempre que pretenda aumentar sua produtividade, preocupação esta, mais dos planejadores do setor saúde.

WITT, A. - Importance and use of the informal organization. Rev. Saúde públ., S. Paulo, 3(2) :203-212, dez. 1969.

Summary - Beside the formal organization there exists the very powerful informal one. There is a series of similarities between them, of which the following stand out: a structure of relationships, a system of control, communication, persons with authority, perception of the consequences of an act, relative permanence of the members and possibility of graphic representation. Since the informal organization is undestructible, it is reccmmended that the same organization be used by the formal, which is viable, bringing general benefits. Some forms of informal organization study are presented in the present paper.

\section{REFERENCIAS BIBLIOGRAFICAS}

1. ARGYRIS, C. - Personalidade e organização: o conflito entre o sistema $e$ a organização. Rio de Janeiro, Ed. Renes, 1969.

2. BARNARD, C. I. - The functions of the executive. Cambridge, Harvard Univ. Press, 1938: Apud KOONTZ, H. \& O'DONNEL, C. - Principios de administração. São Paulo, Livr. Pioneira Ed., 1962. p. 316.

3. DICIONARIO de sociologia, Rio de Janeiro, Ed. Globo, 1963.

4. GANGULI, H. G. - Structure and processes of organization. New York, Asia Publ. House, 1964.

5. HAIRE, M. - Psicologia aplicada $\grave{a} a d-$ ministração. São Paulo, Livr. Pioneira Ed., 1969.

6. KLUCKHOHN, F. - O método de "observacão participante" no estudo das pequenas comunidades. Relacões Humanas, 8:52-66, abr./agô. 1965.

7. LIKERT, R. - New patterns of management. New York, McGraw-Hill, 1961. Apud HAIRE, M. - Psicologia aplicada à administração. São Paulo, Livr. Pioneira Ed., 1969.

8. MILLER, D. C. \& FORM, W. H. Industrial sociology. Apud BROWN, J. A. C. - A psicologia social da indústria: relacōes humanas na fábrica. São Paulo, Ed. Atlas, 1967. p. 105.

9. PFIFFNER, J. M. \& SHERWOOD, F. P. - Organização administrativa. Săo Paulo, Bestseller Import. Livr., 1965.

10. PUIGVERT, A. \& LA BARCA, C. de Manual de relaciones humanas. Madrid, Aguilar, 1967. 